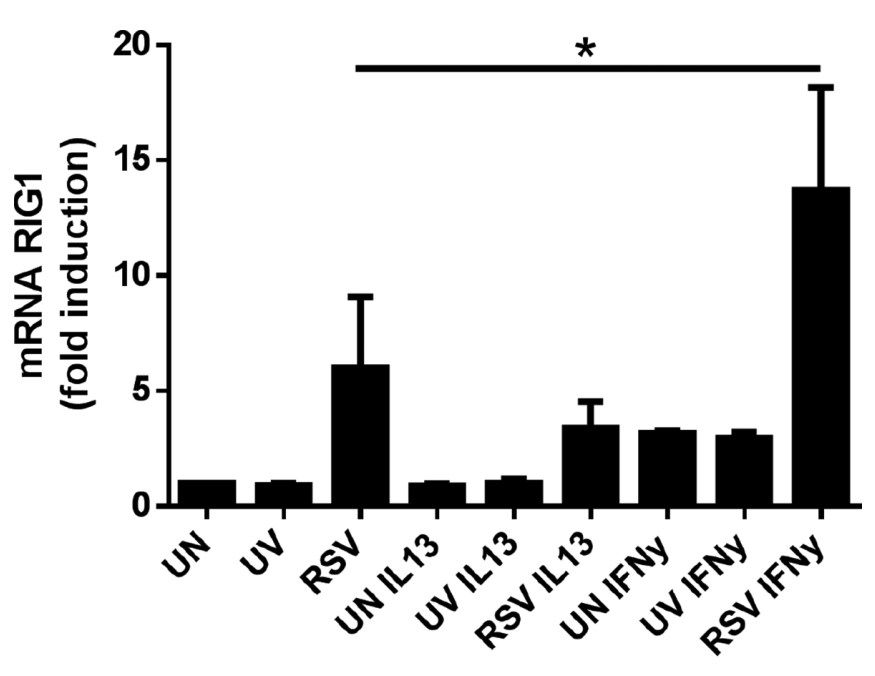

AALEB

Abstract S129 Figure 1 RIG1 expression in RSV infected and primed AALEB by RTPCR. AALEB were pre-treated for $24 \mathrm{~h}$ with $10 \mathrm{ng} / \mathrm{ml}$ IFNy or IL-13, $10 \mathrm{ng} / \mathrm{ml}$. RNA was extracted and reverse transcribed

UN: no infected, UV: inactivated RSV, RSV: Respiratory Syncytial Virus, IL13: Interleukine 13, IFNy: Interferon gamma. Data analysed by one-tailed paired $t$ test. ${ }^{*} p<0.05$, $(n=4)$.

development of a long term abnormality which is a hallmark of asthma.

We optimised an in-vitro model using AALEB, human immortalised bronchial epithelial-derived cells which were pre-treated for $24 \mathrm{~h}$ with cytokines that mimic Th1 environment (IFNy, 10 $\mathrm{ng} / \mathrm{ml}$ ) and Th2 (IL-13, $10 \mathrm{ng} / \mathrm{ml}$ ) before being infected with RSV A, MOI=2 for $48 \mathrm{~h}$. Quantitative real-time PCR with Taqman primers was used to assess expression of innate genes. Cells were collected after $48 \mathrm{~h}$ and stored in Trizol. Chromatin Immuno Precipitation (ChIP) with antibodies against histone modifications was used to assess epigenetic controls. In order to confirm epigenetic regulation of innate genes we used a panel of HAT, HDAC and histone demethylase inhibitors.

We initially studied the impact of cytokines on a range of innate anti-viral genes. RIG1 was differentially expressed and reductions in expression associated with higher viral titres. IFNy priming induced increases in RIG1 mRNA at $48 \mathrm{~h}$ that correlated at the promoter with enrichment of $\mathrm{H} 3 \mathrm{~K} 9 \mathrm{ac}$ and RNApolII (active-promoters) and reduction of $\mathrm{H} 3 \mathrm{~K} 9 \mathrm{me} 3$ (repressive-promoters). We observed a statistically significant increase of RIG1 expression by IFN $\gamma$ when co-incubated with SAHA (HDAC I and II inhibitors) and JIB-04 (Pan-Jumanji histone demethylase inhibitor). No effects of Th2 priming were seen at the level of antiviral responses.

This in-vitro study suggests the inflammatory environment of naive epithelial cells can induce epigenetic modulation of innate immune responses at the level of histone methylation and acetylation and hence potentially lead to long term impacts on antiviral immunity. The presence of a Th1 milieu appears key to the development of effective anti-viral responses.

\section{S130 TNF $\alpha$ DRIVEN CAR PHOSPHORYLATION PROMOTES TRANS EPITHELIAL MIGRATION OF LEUKOCYTES}

${ }^{1} \mathrm{AP}$ Hicks, ${ }^{1} \mathrm{P}$ Morton, ${ }^{1} \mathrm{~A}$ Noble, ${ }^{2} \mathrm{E}$ Raynor, ${ }^{1} \mathrm{M}$ Parsons, ${ }^{1} \mathrm{G}$ Santis. ${ }^{1}$ King's College London, London, UK; ${ }^{2}$ Public Health England, Salisbury, UK

10.1136/thoraxjnl-2014-206260.136
Transepithelial migration (TEpM) of leukocytes during the inflammatory process requires engagement with receptors expressed on the basolateral surface of the epithelium. One such receptor is Coxsackie and Adenovirus Receptor (CAR) which binds to Junction Adhesion Molecule - L (JAM-L) on leukocytes during TEpM. Here we provide the first evidence that TEpM of THP1 cells requires, and is controlled by phosphorylation of the cytoplasmic tail of CAR. Our in-vitro data shows that these leukocyte cells can adhere to an epithelial layer but where the cytoplasmic tail of CAR is prevented from undergoing phosphorylation the leukocytes are unable to transmigrate. Furthermore we show that this CAR phosphorylation step is driven by TNF $\alpha$ signalling via a TNFR1-PI3K-PKC $\delta$ dependent signalling pathway. Interestingly our work demonstrates that THP1 cells can secrete TNF $\alpha$ thereby activating the CAR phosphorylation pathway leading to TEpM without addition of exogenous $\mathrm{TNF} \alpha$ but where TNF $\alpha$ is added this process is augmented. We also use a mouse model to confirm that CAR phosphorylation in response to inflammatory stimuli occurs in-vivo. Both acute (a $24 \mathrm{~h}$ inhaled TNF $\alpha$ challenge) and chronic (a 34 day ovalbumin challenge) inflammatory conditions are studied. Using confocal microscopy techniques we show that the cytoplasmic tail of CAR is phosphorylated. Specifically this is seen at the cell membrane of epithelial cells of bronchioles with associated inflammatory cells in the interstitium. Taken together these data describe a novel method for the control of TEpM by transmigrating leukocytes that can also be heightened by the presence of pro-inflammatory cytokines during inflammation. This provides a novel target for controlling inflammation at the epithelium, a key component of the pathogenesis of many diseases including asthma.

\section{S131 PERIPHERAL BLOOD MONONUCLEAR CELLS FROM CHILDREN WITH SEVERE ASTHMA EXHIBIT AN IMPAIRED CORTICOSTEROID SENSITIVITY, WHICH ALSO CORRELATES WITH INCREASING BODY MASS INDEX}

N Yemula, E Gaillard, Y Amrani. Department of Infection, Immunity and Inflammation, University of Leicester, Leicester, UK

\subsection{6/thoraxjnl-2014-206260.137}

Introduction Corticosteroid (CS) insensitivity contributes to the difficulty in managing children with severe asthma. ${ }^{1}$ A better understanding of the molecular mechanisms driving this defective response could provide novel therapeutic options for these patients. Peripheral blood mononuclear cells (PBMCs) from adults with severe asthma have been used to demonstrate an impaired sensitivity to CS, enabling the delineation of potential underlying mechanisms. Whether CS insensitivity exists in PBMCs from severely asthmatic children, however, requires further validation.

Objective To determine whether PBMCs from children with severe asthma have an impaired in vitro responsiveness to corticosteroids.

Methods We conducted an observational feasibility study comparing the corticosteroid sensitivity of PBMCs from asthmatic children on British Thoracic Society treatment step 4-5 (n=7) with healthy controls $(\mathrm{n}=5)$. PBMCs from $5 \mathrm{ml}$ of venous blood were plated in the presence of $100 \mathrm{ng} / \mathrm{ml}$ of lipopolysaccharide (LPS), and in the absence or presence of either $10^{-8} \mathrm{M}$ or $10^{-6} \mathrm{M}$ of dexamethasone (DEX). ELISA assays were used to determine the levels of TNF- $\alpha$ and IL- 8 , and the $\%$ suppression of these by DEX. Pearson product-moment correlation tests 
were conducted to determine the correlation between in vitro CS sensitivity and different clinical parameters.

Results There was no difference in baseline or LPS-induced cytokine release from PBMCs between the two groups. The inhibition of TNF- $\alpha$ release by DEX was significantly diminished in children with asthma compared to healthy controls at $10^{-8} \mathrm{M}$ concentration $(p=0.018)$ but no differences were noticed at $10^{-6} \mathrm{M}$ concentration, or on LPS-induced IL-8 production. A significant inverse correlation between $\%$ inhibition of TNF- $\alpha$ and body mass index (BMI) at $10^{-8} \mathrm{M}(\mathrm{r}=-0.84, p=0.02)$ and $10^{-6} \mathrm{M}$ DEX $(\mathrm{r}=-0.82, p=0.02)$ was found.

Conclusions Our results show the existence of an impaired CS sensitivity in PBMCs from children with severe asthma, suggesting that these cells can be used for mechanistic investigations. Interestingly, we observed a negative correlation between CS sensitivity and BMI, a novel in vitro finding which supports the association between overweight/obese asthmatic children and a decreased clinical response to CS therapy. Together, these results merit further studies with a larger sample size.

\section{REFERENCES}

1 Chung KF et al. ERJ 2014;43:343-373

\section{S132 SPUTUM AND BRONCHIAL BIOPSY EXPRESSION OF 8- OX0-7, 8-DIHYDRO-2'-DEOXYGUANOSINE (8-OXODG) IN ASTHMA IS RELATED TO NEUTROPHILIC INFLAMMATION AND POOR ASTHMA CONTROL}

${ }^{1}$ DJE Goold, ${ }^{1} V$ Mistry, ${ }^{1} A$ Singapuri, ${ }^{2} \mathrm{M}$ Cooke, ${ }^{1} \mathrm{R}$ Berair, ${ }^{1} \mathrm{CE}$ Brightling. ${ }^{1}$ Institute for Lung Health, NIHR Respiratory Biomedical Research Unit, Department of Infection, Immunity and Inflammation, University of Leicester and Department of Respiratory Medicine University Hospitals of Leicester NHS Trust, Leicester, UK; ${ }^{2}$ Oxidative Stress Group, Department of Cancer Studies and Department of Genetics, University of Leicester, Leicester, UK Department of Health Sciences, University of Leicester, Leicester, UK

\subsection{6/thoraxjnl-2014-206260.138}

Introduction and objectives Oxidative stress has been implicated in the pathogenesis of asthma. Validated sputum biomarkers are required to assess this and its relationship to other clinical variables.

We sought to compare sputum and bronchial 8-oxodG expression in asthma and health; assess the sputum repeatability; and explore its relationship with induced sputum inflammatory cells counts and exacerbations.

Methods Asthmatics and healthy controls were recruited from a single centre and underwent clinical characterisation including sputum induction (asthma $\mathrm{n}=58$, health $\mathrm{n}=27$ ) and bronchial biopsy (asthma $\mathrm{n}=16$, health $\mathrm{n}=10$ ).

Sputum and epithelial 8-oxodG expression was measured by ELISA and Immunohistochemistry respectively. Sputum asthmatics were assessed at a repeat stable visit at 6 months.

Results Between health and asthma, there were no significant differences in the median (IQR) sputum 8-oxodG levels [12 (16) $\mathrm{ngml}^{-1}$ vs. 11 (15) $\mathrm{ngml}^{-1}, \mathrm{p}=0.36$ ] or the mean (SEM) percentage area of epithelium reaching threshold intensity for 8 oxodG [2.0 (0.7)\% vs. $4.4(1.0) \%, \mathrm{p}=0.12]$.

Asthma sputum 8-oxodG correlated with the sputum total cell count $\left(r_{\mathrm{s}}=0.53, \mathrm{p}<0.01\right)$, sputum neutrophils $\left(r_{\mathrm{s}}=0.27, \mathrm{p}\right.$ $=0.04)$, sputum macrophages $\left(r_{\mathrm{s}}=-0.31, \mathrm{p}=0.02\right)$ and serum $\operatorname{IgE}\left(r_{\mathrm{s}}=-0.27, \mathrm{p}=0.04\right)$. Epithelial 8-oxodG correlated to the number of exacerbations in the previous year $\left(\mathrm{r}_{\mathrm{s}}=0.70, \mathrm{p}<0.01\right)$ and the ACQ $6\left(r_{s}=-0.52, p=0.04\right)$.
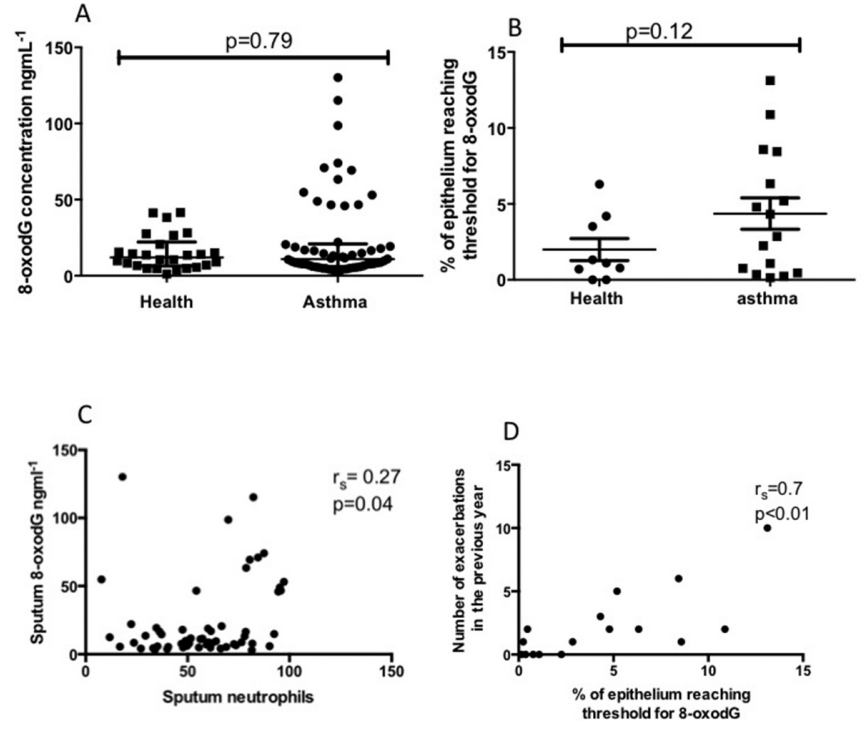

Abstract S132 Figure 1 Scatter plots of A) Sputum 8-oxodG in health vs. asthma; B) Epithelial 8-oxodG in health and asthma; C) Sputum 8-oxodG vs. sputum neutrophils and D) Epithelial 8- oxodG vs. the number of exacerbations in the previous year.

Spearman's rank correlation coefficients are also given. Comparisons were made using $t$ tests and Mann Whitney $U$ tests for parametric and non-parametric data respectively

The upper 95th confidence interval of sputum 8-oxodG and epithelium 8-oxodG reaching threshold in healthy controls was used to split asthma patients into 8-oxodG high and low groups. The sputum 8-oxodG ${ }^{\text {high }}$ group $(\mathrm{n}=13)$ had significantly higher sputum total cells 8.08 [8.41] $\times 10^{6} \mathrm{~g}^{-1}$ vs. 2.25 [2.91] $\times 10^{6} \mathrm{~g}^{-1}$, $\mathrm{p}<0.01$, higher sputum neutrophils $(82.25[32.75] \%$ vs. 55.50 $[29.75] \%, \mathrm{p}<0.01)$ and lower serum IgE $\left(30\right.$ [76.50] $\mathrm{KUL}^{-1}$ vs. 157 [212.90] $\left.\mathrm{KUL}^{-1}, \mathrm{p}<0.01\right)$. The epithelial 8-oxodG high group $(\mathrm{n}=8)$ had significantly more exacerbations $3.9(0.3)$ vs. $0.5(0.3) \mathrm{p}<0.01$ and a lower ACQ 6 score $1.4(0.3)$ vs. 2.4 (0.3) $\mathrm{p}=0.04$.

In the asthmatic group, the intra-class correlation coefficient of sputum 8-oxodG between the 2 visits was 0.51 ( $p<0.01$ ).

Conclusions 8 -oxodG expression in sputum and bronchial biopsies was not different between asthma and health, although we did identify an 8-oxodG ${ }^{\text {high }}$ group in asthma. Interestingly, expression in asthma was associated with neutrophilic inflammation and poor asthma control.

\section{S133 32 -ADRENERGIC RECEPTOR GLY16ARG POLYMORPHISM IS NOT ASSOCIATED WITH IMPAIRED ASTHMA CONTROL IN CORTICOSTEROID TREATED ADULT ASTHMATICS}

${ }^{1} \mathrm{~B}$ Griffin, ${ }^{2} \mathrm{~A}$ Manoharan, ${ }^{2}$ WJ Anderson, ${ }^{2} \mathrm{~J}$ Lipworth, ${ }^{2} \mathrm{BJ}$ Lipworth. ${ }^{1}$ University of St. Andrews, St. Andrews, UK; ${ }^{2}$ University of Dundee, Dundee, UK

\subsection{6/thoraxjn-2014-206260.139}

Introduction The Arg-16 $\beta_{2}$-adrenergic receptor allele is associated with increased exacerbations in asthmatic children exposed to combination therapy with long-acting beta-agonists (LABA) and inhaled corticosteroids (ICS). ${ }^{1}$ We evaluated whether the Gly16Arg polymorphism is associated with impaired asthma control in ICS treated adult asthmatics and whether this was influenced by concomitant LABA use. 